\title{
Two Toxins from Conus striatus that Individually Induce Tetanic Paralysis
}

\author{
Wayne P. Kelley ${ }^{\ddagger} \S$, Joseph R. Schulz ${ }^{\#}{ }^{\wedge}$, Jennifer A. Jakubowski ${ }^{\ddagger}$, William F. Gilly\#, and \\ Jonathan V. Sweedler ${ }^{\star}, \ddagger$ \\ Department of Chemistry and The Beckman Institute for Advanced Science and Technology, \\ University of Illinois Urbana-Champaign and Hopkins Marine Station, Department of Biological \\ Sciences, Stanford University
}

\begin{abstract}
We describe structural properties and biological activities of two related O-glycosylated peptide toxins isolated from injected (milked) venom of Conus striatus, a piscivorous snail that captures prey by injecting a venom that induces a violent, spastic paralysis. One 30-amino-acid toxin is identified as $\kappa$ A-SIVA (termed s4a here), and another 37 -amino-acid toxin, s4b, corresponds to a putative peptide encoded by a previously reported cDNA. We confirm the amino acid sequences and carry out structural analyses of both mature toxins using multiple mass spectrometric techniques. These include electrospray ionization ion trap mass spectrometry and nanoelectrospray techniques for small volume samples, as well as matrix-assisted laser desorption/ionization time-of-flight mass spectrometric analysis as a complementary method to assist in the determination of post-translational modifications, including O-linked glycosylation. Physiological experiments indicate that both s4a and $\mathrm{s} 4 \mathrm{~b}$ induce intense repetitive-firing of the frog neuromuscular junction, leading to a tetanic contracture in muscle fiber. These effects apparently involve modification of voltage-gated sodium channels in motor axons. Notably, application of either s4a or s4b alone mimics the biological effects of the whole injected venom on fish prey.
\end{abstract}

Toxic components of Conus venoms are predominately small peptides (12-50 amino acids), most of which are extensively cross-linked with internal disulfide bonds that add rigidity and stability to the peptide and constrain its conformation for optimal interaction with specific receptors. In addition to disulfide linkages, cone snail peptides have an unprecedented density and diversity of other amino acid modifications that occur after translation of the peptide chain. It is likely that many of these post-translational modifications (PTMs) also confer specificity to the peptide toxins, which can be highly selective for certain receptor subtypes $(1,2)$. For

\footnotetext{
*To whom correspondence should be addressed. E-mail: sweedler@scs.uiuc.edu. Tel: (217) 244-7359. Fax: (217) 244-8068. \$Department of Chemistry and The Beckman Institute for Advanced Science and Technology, University of Illinois at UrbanaChampaign

Current address: GlaxoSmithKline, Pharmaceutical Development, 709 Swedeland Road, King of Prussia, PA. 19406

\#Department of Biological Sciences, Hopkins Marine Station, Stanford University.

${ }^{\wedge}$ Current address: Occidental College, Los Angeles, CA 90041

\$This work was supported by NIH grant NS 31609 and NSF grant CHE 04-00768 (to JVS), Kirschstein NRSA 5F32NS43938 (to JRS), NSF grant IBN 0131788 (to WFG), and a fellowship from the Merck Research Laboratories (to JAJ).

The characterization of two $C$. striatus paralytic toxins

${ }^{1}$ Abbreviations: ACN, acetonitrile; AP, action potential; CHCA, $\alpha$-cyano-4-hydroxycinnamic acid; CID, collisional-induced dissociation; DRG, dorsal root ganglion; EPP, end plate potential; ESI MS, electrospray ionization ion trap mass spectrometry; HPLC, high performance liquid chromatography; MALDI-TOF MS, matrix-assisted laser desorption/ionization time of flight mass spectrometry; $\mathrm{MS}^{2}$, fragmentation of an MS-isolated ion and the subsequent MS-based measurement of a resulting product ion; $\mathrm{MS}^{3}$, three-stage mass analysis experiment concluding with the measurement of an $\mathrm{MS}^{2}$ fragment ion; NSI MS, nanospray ionization mass spectrometry; TFA, trifluoroacetic acid;
} 
example, a subset of the $\mu$-type toxins from $C$. geographus blocks voltage-gated sodium $\left(\mathrm{Na}_{\mathrm{v}}\right)$ channels in frog skeletal muscle $\left(\mathrm{Na}_{\mathrm{v}} 1.4\right)$ but has essentially no effect on other subtypes of $\mathrm{Na}_{\mathrm{v}}$ channels expressed in peripheral nerve (3). This toxin produces a flaccid paralysis of an envenomated fish.

Of the more than 500 species in the genus Conus, only about $10 \%$ feed exclusively on fish, and these species form at least three clades based on molecular genetic analysis (4). Venoms of piscivorous snails contain peptides that selectively target a variety of voltage- and ligandgated ion channel types in vertebrates, including voltage-gated $\mathrm{Na}$, calcium $\left(\mathrm{Ca}_{\mathrm{v}}\right)$ and potassium $\left(\mathrm{K}_{\mathrm{V}}\right)$ channels as well as nicotinic acetylcholine $(\mathrm{nACh})$ receptors (5). Peptide toxins from piscivorous snails have proven valuable in the identification and localization of ion channel subtypes as well as for the development of novel therapeutics (6-8).

C. striatus belongs to a clade of piscivorous snails from the Indo-Pacific that includes $C$. catus, $C$. magus, $C$. consors, $C$. stercumuscarum, and $C$. striolatus. Each of these species has been observed to elicit a spastic (rigid) paralysis upon injection of venom into a fish during prey capture $(1,9,10)$. In this work, we characterize two O-glycosylated toxins isolated from C. striatus venom, designated $\mathrm{s} 4 \mathrm{a}$ and $\mathrm{s} 4 \mathrm{~b}$, both in terms of structure and molecular target. Either of these two peptides is capable of inducing repetitive firing in nerve and producing a tetanic paralysis that is comparable to that seen with injected venom. Craig and coworkers originally described the s4a toxin, suggested block of $\mathrm{K}_{\mathrm{v}}$ channels to be the mode of action and therefore named the peptide $\kappa A-S I V A(11)$. However, a definitive molecular target for $\kappa A-S I V A$ has not been identified (6). Additionally, some of the researchers in the original study have since concluded that the $\kappa$ A-SIVA toxin may affect $\mathrm{Na}_{\mathrm{v}}$ channels in a manner similar to that of a $C$. consors toxin with a homologous scaffold structure, noting that further investigation of the toxin is warranted (6). We demonstrate here that $\mathrm{Na}_{\mathrm{v}}$ channels are indeed involved in the action of this toxin from $C$. striatus and that this peptide alone can mimic the observed action of the injected venom. Given the assessment that $\mathrm{K}_{\mathrm{V}}$ channels are not targeted, peptide kA-SIVA is renamed $\mathrm{s} 4 \mathrm{a}$, in keeping with current conotoxin nomenclature conventions (12).

\section{MATERIALS AND METHODS}

\section{Compounds and Solutions}

Trifluoroacetic acid (TFA), glacial acetic acid, formic acid, 4-vinylpyridine (4-VP), guanidine HSCN, EDTA (disodium salt), bovine insulin and $\alpha$-cyano-4-hydroxycinnamic acid (CHCA) were obtained from Sigma-Aldrich Chemical Co. (St. Louis, MO). Ammonium bicarbonate, HPLC-grade acetonitrile (ACN) and methanol were obtained from Fisher Scientific (Pittsburgh, PA). Burdick and Jackson water (Muskegon, MI) was used for peptide-trap rinsing and HPLC solvents. Aplysia californica peptides (acidic peptide and $\alpha$-bag cell peptide residues 1-9) were obtained from American Peptide Company (Sunnyvale, CA). Immobilized tris-(2carboxyethyl) phosphine disulfide reducing gel (TCEP) was purchased from Pierce (Rockford, IL).

\section{cDNA Cloning}

Total venom duct RNA was isolated from five individual C. striatus, and the mRNA purified. Double-stranded oligo-dt primed cDNA was prepared and cloned directionally into the pSport2 (Invitrogen Corporation, Carlsbad, CA) cloning vector in order to create a venom duct plasmid cDNA library. One-hundred and twenty-eight random clones were sequenced from the $5^{\prime}$-ends of the cDNA inserts. 


\section{Isolation of Toxins from Injected Venom}

Live C. striatus specimens were collected from Tutuila Island, American Samoa, and maintained at Hopkins Marine Station in closed tanks at $27{ }^{\circ} \mathrm{C}$ for up to six months, and the injected venom collected. Injected venom was obtained by a milking procedure as described elsewhere $(13,14)$. Briefly, a live fish was used to arouse the snail, inducing it to puncture a latex membrane covering a sample vial with the radular tooth and inject venom. Several milkings from an individual snail were combined and injected onto a Rainin $\mathrm{C}_{18}$ column (4.6 $\times 150 \mathrm{~mm}, 5-\mu \mathrm{m}$ particle diameter, 30-nm pore size) (Rainin Instrument, LLC, Oakland, CA) using a LKB Bromma HPLC system (Bromma, Sweden). A gradient was developed from 15 to $30 \%$ ACN over $30 \mathrm{~min}$. Fractions from these separations could be further separated by changing the organic modifier. In some cases, single stage separations were sufficient to resolve the two peptides and were performed using a Vydac $\mathrm{C}_{18}$ column $(4.6 \times 150 \mathrm{~mm}, 5-\mu \mathrm{m}$ particle diameter, 30-nm pore size) (Grace Vydac, Hesperia, CA) with a gradient from 15 to $30 \%$ ACN over 50 min.

\section{MALDI-TOF MS Experiments}

(A) Linear mode MS for Identification of Purified Fractions-A $0.5-\mu \mathrm{L}$ aliquot of each sample was spotted onto a gold-plated target along with $0.5 \mu \mathrm{L}$ of a matrix (15 mg CHCA, $600 \mu \mathrm{L}$ acetonitrile, $400 \mu \mathrm{L}$ water, and $3 \mu \mathrm{L}$ TFA). Matrix-assisted laser desorption/ionization (MALDI) mass spectrometry (MS) was used to obtain mass spectra with a Voyager DE STR (PE Biosystems, Framingham, MA) time-of-flight (TOF) mass spectrometer equipped with delayed ion extraction. A pulsed nitrogen laser $(337 \mathrm{~nm})$ was used as a desorption/ionization source, and positive-ion mass spectra were acquired using linear mode. Each representative mass spectrum shown is the smoothed average of 128-256 laser pulses. External mass calibration was performed using a mixture of synthetic peptide standards (PE Biosystems).

(B) Reflectron MALDI-TOF MS for Accurate Mass Determination-Accurate mass spectra were obtained by pipetting a $0.5-\mu \mathrm{L}$ aliquot of each sample onto a gold-plated target and adding $0.5 \mu \mathrm{L}$ of the CHCA matrix on top. A standard mixture consisting of bovine insulin (120 pmol per $\mu \mathrm{L}$ ), acidic peptide (120 pmol per $\mu \mathrm{L})$, angiotensin I (60 pmol per $\mu \mathrm{L})$, and $\alpha$ bag cell peptide residues 1-9 (60 pmol per $\mu \mathrm{L})$, was spotted at the edge of the target well, topped with CHCA matrix, and then mixed with the sample to be analyzed. Manual calibration of the instrument was performed utilizing the known monoisotopic mass values for the internal standards. Positive polarity, reflectron-mode spectra were collected using 500 laser pulses averaged per spectrum. No smoothing or post-collection processing was performed other than automatic application of the internal standard adjustments by the Voyager Data Explorer software (PE Biosystems).

\section{Microbore HPLC-ESI MS of Injected Venom}

Injected venom samples from individual snails were pooled (about four milkings and total volume of $12-15 \mu \mathrm{L}$ ) and stored at $-80^{\circ} \mathrm{C}$ until ready for use. An HPLC electrospray ionization (ESI) MS experiment typically utilized $5 \mu \mathrm{L}$ of this material, which was loaded into a peptide trap in line with the injection loop and rinsed with pure $\mathrm{H}_{2} \mathrm{O}$ to remove salts. Separations were performed using a MAGIC 2002 microbore HPLC system (Michrom BioResources, Auburn, CA). Injection into the column (Vydac, PepMap ${ }^{\mathrm{TM}} \mathrm{C}_{18} ; 1 \mathrm{~mm} \times 150 \mathrm{~mm}, 3-\mu \mathrm{m}$ particle diameter, 10 -nm pore size) was made at a uniform flow rate of $30 \mu \mathrm{L}$ per min. The mobile phase consisted of solvent A: $95 \% \mathrm{H}_{2} \mathrm{O}, 5 \% \mathrm{ACN}, 0.1 \%$ acetic acid (v/v) and $0.02 \%$ TFA (v/ v) and $\mathbf{B}: 10 \% \mathrm{H}_{2} \mathrm{O}, 90 \% \mathrm{ACN}, 0.1 \%$ acetic acid (v/v) and $0.014 \% \mathrm{TFA}(\mathrm{v} / \mathrm{v})$. A gradient was developed from 5 to $15 \%$ solvent $\mathbf{B}$ in $5 \mathrm{~min}$ and $15-45 \% \mathbf{B}$ in an additional $30 \mathrm{~min}$.

For online MS detection, the column was connected directly to the atmospheric pressure inlet port of an LCQ Deca, ESI-ion trap mass spectrometer (Thermo, San Jose, CA). The MS method 
employed a spray voltage of $4.3 \mathrm{kV}$, a capillary temperature of $220^{\circ} \mathrm{C}$, capillary voltage of 21 $\mathrm{V}$, and a tube-lens offset of $10 \mathrm{~V}$. By default, automatic gain was used to control injection of ions into the trap. Using the Xcalibur software (Thermo), a modified triple-play data-dependent acquisition control with dynamic exclusion was developed. Briefly, a full scan MS was followed by a zoomscan and then $\mathrm{MS}^{2}$ of the largest peak in the full scan.

\section{Reduction/Alkylation of Conotoxins}

(A) HPLC Conditions and Retention Time of the Native Toxins-A vial containing either the $s 4 \mathrm{a}$ or $\mathrm{s} 4 \mathrm{~b}$ material was concentrated to near dryness using a SpeedVac

(ThermoSavant, Holbrook, NY). Water $(10 \mu \mathrm{L})$ was added to the vial, and the sample gently vortexed and briefly sonicated. A $2.5 \mu \mathrm{L}$ aliquot of the material was fractionated using the same peptide trap, PepMap column, microbore HPLC system, and solvents as discussed above. For the s4a peptide, a gradient was developed at a uniform flow rate of $30 \mu \mathrm{L} / \mathrm{min}$ with an initial wash phase that consisted of $1 \% \mathbf{B}$ for $10 \mathrm{~min}$, increasing to $20 \% \mathbf{B}$ over $20 \mathrm{~min}$, and to $30 \% \mathbf{B}$ in $10 \mathrm{~min}$. A gradient was then developed from $30 \% \mathbf{B}$ to $45 \%$ over $30 \mathrm{~min}$, followed by a gradient from $45 \%$ to $65 \%$ B over 5 min. Fractions were collected on a Gilson FC 203B fraction collector (Middletown, WI) and peaks were identified by MALDI-TOF MS. The peak corresponding to the $\mathrm{s} 4 \mathrm{~b}$ peptide was separated in a similar fashion but with an optimized gradient consisting of 1 to 5\% $\mathbf{B}$ over $20 \mathrm{~min}$, increasing to 15\% $\mathbf{B}$ after $30 \mathrm{~min}$ and $30 \% \mathbf{B}$ at $40 \mathrm{~min}$, and finally increasing from 30 to $37 \% \mathbf{B}$ over $20 \mathrm{~min}$.

(B) Linear Mode MALDI-TOF MS for Monitoring Fractions-Positive polarity, linear mode MALDI-TOF MS spectra were acquired as detailed previously. Monitoring of the reduced and alkylated material was performed without any additional sample treatment.

(C) Reduction of Conotoxins-An estimated 800 pmol of s4a and 150 pmol of s4b were subjected to reduction/alkylation. The samples were concentrated to near dryness using a SpeedVac concentrator and then resuspended in $100 \mu \mathrm{L}$ of $6 \mathrm{M}$ guanidine HSCN, $0.1 \mathrm{M}$ ammonium bicarbonate, and $10 \mu \mathrm{M}$ EDTA. In a separate vial, $200 \mu \mathrm{L}$ of immobilized TCEP gel was mixed with an equal volume of $20 \mathrm{mM}$ EDTA. The TCEP vial was vortexed and centrifuged at $2500 \mathrm{RCF}$ for $2 \mathrm{~min}$, and the supernatant discarded. Another $200 \mu \mathrm{L}$ of $20 \mathrm{mM}$ EDTA was added to the gel and the rinse repeated. Sample was then added to the gel. Nitrogen gas was blown over the vial before it was sealed, the sample gently agitated for $15 \mathrm{~min}$, and then centrifuged at $2500 \mathrm{RCF}$ for $2 \mathrm{~min}$. The supernatant was retained for analysis in a separate vial. A final rinse was carried out by adding $100 \mu \mathrm{L}$ of $0.05 \mathrm{M}$ ammonium bicarbonate to the TCEP gel, vortexing, and centrifuging as described above.

(D) Alkylation-Temperature in the SpeedVac was set at $45^{\circ} \mathrm{C}$ and the concentrator shielded from light in order to use it in the light-sensitive alkylation procedure. An addition of $4 \mu \mathrm{L} 4$ VP at room temperature was made to the sample. Nitrogen was blown over the sample and the vial wrapped in foil, vortexed, and placed in the heated SpeedVac for $2 \mathrm{~h}$.

(E) Purification of Alkylated Material-Prior to the purification of the alkylated sample, $0.1 \%$ TFA $(0.2 \mu \mathrm{L})$ was added in order to acidify the mixture. The sample was loaded into the peptide trap and rinsed with $400 \mu \mathrm{L}$ of water. For s $4 \mathrm{a}$, the separation was performed as described previously for the untreated peptide. The alkylated $\mathrm{s} 4 \mathrm{~b}$ sample was purified as described above for the native peptide. MALDI-MS was employed to identify peaks of interest. Alkylated products for both peptides exhibited slightly greater hydrophilicity than their precursors. 


\section{Tandem MS Experiments for Sequence Verification}

In order to perform in-depth, collisional sequencing experiments while utilizing minimal sample volume, the ion trap instrument was fitted with a static nanospray source supplied by the vendor. A 5- $\mu \mathrm{L}$ aliquot of a second-stage HPLC fraction corresponding to the mass of interest was concentrated via the SpeedVac and reconstituted in $10 \mu \mathrm{l}$ of a methanol/water mixture $(50 / 50(\mathrm{v} / \mathrm{v})$ with $0.1 \%$ formic acid). The sample was loaded into a tapered, platinumcoated borosilicate nanospray emitter, PicoTip ${ }^{\mathrm{TM}}$ (New Objective, Woburn, MA), and a spray voltage of $1.5 \mathrm{kV}$ was applied. The capillary temperature was set at $200{ }^{\circ} \mathrm{C}$ and the capillary potential at $39 \mathrm{~V}$. The optimized spray voltage and ion optic settings were adjusted using the auto-tune function. Once a full scan was observed in real time, $\mathrm{MS}^{2}$ and $\mathrm{MS}^{3}$ experiments were directed by manually inputting the mass-to-charge $(\mathrm{m} / \mathrm{z})$ values.

Tandem MS (MS/MS) sequencing experiments used a mass isolation width of $1.5 \mathrm{~m} / \mathrm{z}$ for the precursor ion and $1.0 \mathrm{~m} / \mathrm{z}$ for resulting $\mathrm{MS}^{2}$ fragment ions to be retained in the trap. An activation Q (ion instability parameter) value of 0.25 at an activation time of $30 \mathrm{msec}$ was utilized. The normalized collisional energy was set at $35 \%$ for both $\mathrm{MS}^{2}$ and $\mathrm{MS}^{3}$ experiments. Spectra were acquired for 2 min or longer resulting in a minimum of 164 scans. Sequence verification was facilitated using the online Protein Prospector, MS-Product program (15).

\section{Electrophysiology}

Sartorius or cutaneous pectoris muscles with intact nerve supplies were dissected from frogs (Rana pipiens) and bathed in a standard saline containing (in $\mathrm{mM}$ ): $120 \mathrm{NaCl}, 2.5 \mathrm{KCl}, 2.0$ $\mathrm{CaCl}_{2}, 5$ HEPES (pH 7.2). In some experiments, $12 \mathrm{mM}$ tetraethylammonium chloride (TEA $\mathrm{Cl}$ ) was added with an equivalent reduction in the concentration of $\mathrm{NaCl}$. The membrane potential of muscle fibers was measured with an intracellular microelectrode filled with $3 \mathrm{M}$ $\mathrm{KCl}$, and neuromuscular transmission was assayed by stimulating the cut ends of the nerves with brief shocks $(0.4 \mathrm{~ms}, 1.5 \mathrm{~V})$ delivered with a suction electrode filled with standard saline. Muscle action potentials (APs) were eliminated by adding the peptide, $2 \mu \mathrm{M} \mu \mathrm{GIIIA}$ (16), to the bath. This peptide from $C$. geographus selectively blocks $\mathrm{Na}_{\mathrm{v}}$ channels in muscle, thus allowing measurement of large end-plate potentials (EPPs) in response to nerve stimulation with no muscle contraction. In some experiments, extracellular focal recordings were made at end-plate regions using a polished glass pipette filled with the same saline used in the bath.

In several experiments, the nerve was isolated in its own bath to permit selective application of toxin to motor axons. This was achieved by placing the muscle and distal nerve trunk in the recording chamber ( $1 \mathrm{~mL}$ volume) and then drawing the cut, proximal end of the nerve into an adjacent $250-\mu \mathrm{L}$ chamber through a Vaseline-gap seal. The endoneural sheath was dissected from a section of nerve in the smaller chamber, and the cut end was drawn into a suction electrode for stimulation in the usual manner. Lack of leakage between the two chambers was confirmed with a dye.

Dorsal root ganglion (DRG) neurons were isolated from individual frog ganglia that had been treated with collagenase Type IA $(1 \mathrm{mg} / \mathrm{mL})$ and non-specific protease Type XIV (5-7 mg/ $\mathrm{mL}$ ) at room temperature for 1-1.5 h (both enzymes from Sigma-Aldrich). After cutting open the capsule surrounding the ganglion, neurons were dissociated by trituration and plated on glass coverslips coated with poly-lysine. Cell cultures were maintained in 50\% L-15 (Gibco, Carlsbad, CA) in standard saline at $4{ }^{\circ} \mathrm{C}$ for several days before use. Conventional whole-cell patch clamp methods were carried out to measure Na currents at $16-18{ }^{\circ} \mathrm{C}$ on cells with no visible axonal processes, as described elsewhere (17). The bath solution contained (in $\mathrm{mM}$ ): $120 \mathrm{NaCl}, 1 \mathrm{CaCl}_{2}, 4 \mathrm{MgCl}_{2}, 10 \mathrm{HEPES}$ (pH 7.2). The internal (pipette) solution contained (in $\mathrm{mM}$ ): $25 \mathrm{NaCl}, 40$ tetramethylammonium fluoride, 40 tetramethylammoniuim aspartate, 10 TEA Cl, 2 EGTA, 1 EDTA, 10 HEPES (pH 7.2). 


\section{RESULTS}

\section{Collection and Purification of Injected Venom}

Injected venom, rather than duct venom, from Conus striatus is studied here, thereby characterizing the unique peptide complement actually employed during prey capture (18). Furthermore, use of crude venom isolated from the venom duct requires sacrifice of the animal. In previous work, we showed that injected venom, collected by milking wild C. striatus, typically contains two predominant peptides, resolved by reverse-phase HPLC (14).

\section{Cloning}

Venom-duct mRNA isolated from individual C. striatus was converted to cDNA and transformed into a plasmid library. Genes encoding peptide toxins were identified by open reading frame and translation analyses. cDNAs encoding peptide toxins represented over half of the randomly selected and sequenced clones. A number of these clones encoded putative amino acid sequences later identified as the peptides s4a and s4b (Figure 1). One sequence contained an open reading frame of 69 amino acids with a structure typical of a conotoxin propeptide, the $\mathrm{C}$-terminal portion of which matched the reported 30-residue sequence of the mature toxin, s4a (KA-SIVA of (11)). A second sequence (s4b) predicted a propeptide of 80 amino acids with the predicted mature peptide of 37 residues (bracketed segments in Figure 1). The cDNA-predicted N-terminal amino acids for $\mathrm{s} 4 \mathrm{a}$ and $\mathrm{s} 4 \mathrm{~b}(\mathrm{Q})$ indicated the likelihood of pyroglutamate (pGlu) occurrence (later labeled as (q) after identification by mass spectrometry) (19). Glycine residues located after the C-terminal cleavage in the s4a- and s4bpredicted sequences are an indication of $\mathrm{C}$-terminal amidation. Previous work by others yielded cDNA sequences from C. striatus identical to those presented here for $\mathrm{s} 4 \mathrm{a}(11,20,21)$ and $\mathrm{s} 4 \mathrm{~b}$ (20).

\section{Amino Acid Analysis}

Each of the two purified fractions was subjected to amino acid analysis. The results matched the predicted residues in the cDNA sequences, expected number of disulfide linkages, and likely PTMs for s4a and s4b. The sequence and amino acid residue matches can be found in supporting information.

\section{Mass Spectrometric Characterization}

Fractions from reverse phase-HPLC separations of injected venom were assayed by MALDITOF MS and ESI MS using an ion trap instrument.

\section{MALDI-TOF MS of Purified Fractions}

The positive-polarity linear-mode MALDI mass spectra from the $s 4 a$ fraction yielded an average $\mathrm{m} / \mathrm{z}$ of approximately 4084 for the predominant peak. Several specific peaks of lower mass in the spectrum (noted in Figure 2A and described below) were consistent with glycosylation of the mature peptide. Within the mass error of linear mode MALDI MS, peaks at 3923 and $3762 \mathrm{~m} / z$ corresponded to the loss of one and two hexose (Hex) units, respectively. A peak observed at $3192 \mathrm{~m} / z$ was consistent with an 892 Da shift from the main peak at 4084 $\mathrm{m} / \mathrm{z}$ due to the loss of an $\mathrm{N}$-acetyl hexosamine-containing moiety, $\mathrm{Hex}_{3}-\mathrm{HexNAc-HexNAc,}$ with a calculated mass of $893 \mathrm{Da}$. Given that there is no N-linked glycosylation consensus sequence (Asn-Xxx-Ser/Thr) in the primary structure of s4a, the glycan must be O-linked via serine or threonine residues. Thus, the peak at 3192 approximated the calculated $\mathrm{M}+\mathrm{H}$ for the s4a peptide based on the predicted amino acid sequence and likely PTMs (pGlu, Hyp, disulfide linkages and amidation) and was further supported by amino acid analysis (see supporting materials). 
Figure 2B illustrates the analogous MALDI-TOF mass spectrum for the $\mathrm{s} 4 \mathrm{~b}$ fraction. The most abundant peak in the spectrum was identified at $4950 \mathrm{~m} / z$. As in the case of s4a, peaks corresponding to the sequential loss of one and two hexose units were also observed (4786 and $4626 \mathrm{~m} / \mathrm{z}$ in Figure 2b), and a peak occurred that was $891 \mathrm{Da}$ smaller than the most abundant peak (4059 vs. $4950 \mathrm{~m} / \mathrm{z}$ in Figure 2B). This smaller mass approximates the calculated M + H mass for the s4b-predicted primary structure (taking into account nominal mass accuracy for linear mode MALDI MS) with the same likely PTMs described above for s4a, and is consistent with the amino acid analysis of s4b. Thus, an O-linked glycosyl group, $\mathrm{Hex}_{3}$-HexNAcHexNAc (893 Da), accounts for the observed average mass for the mature peptide at $4950 \mathrm{~m} /$ $z$.

\section{ESI-Ion-Trap MS to Characterize Glycosylation}

In order to probe $\mathrm{s} 4 \mathrm{a}$ and $\mathrm{s} 4 \mathrm{~b}$ for further evidence of glycosylation, each peptide was subjected to ESI-MS. The O-linked glycosyl modification was found to be much more labile using ESI MS than with MALDI MS. Additionally, the type and intensity of the glycan fragments are highly dependent on ionization and instrumental conditions as well as the peptide sequence (22-24). For both peptides, an $\mathrm{M}+\mathrm{H}$ peak of $893.2 \mathrm{~m} / \mathrm{z}$ (Figure $2 \mathrm{C}$ for s4a and Figure 2D for $\mathrm{s} 4 \mathrm{~b}$ ) corresponded to the released $\mathrm{Hex}_{3}$ HexNAc-HexNAc modification. Furthermore, sequential losses of the glycan subunits are noted in Figure 2C and 2D, demonstrating that the peptide is most likely attached to two HexNAc units in series followed by three hexose units. This type of glycosylation structure was previously observed for KA-SIVA, and the site of sugar attachment was reported to be the serine at position $7 \mathrm{in} \mathrm{s4a,} \mathrm{as} \mathrm{implied} \mathrm{by} \mathrm{a} \mathrm{blank} \mathrm{Edman}$ cycle (11).

Notably, in the HPLC-ESI MS depicted in Figures 2B and 2D, a peak corresponding to the $\mathrm{b}_{5}$ ion was identified for both peptides. The singly charged fragment at $539 \mathrm{~m} / \mathrm{z}$ corresponded to the $b_{5}$ fragment of s4a, qKSLV (where $q$ is pyroGlu), which was adjacent to the portion of the sequence containing the glycosylated serine, -PS§VIT- (where $\S$ is the 892.8 Da O-linked glycosyl group). The $b_{5}$ ion was also readily observed in ESI MS (Figure 2D) and MS ${ }^{2}$ conditions for the $\mathrm{s} 4 \mathrm{~b}$ peptide (qKELV at $581 \mathrm{~m} / \mathrm{z}$ ).

\section{Mass Accuracy Measurements}

MALDI-TOF MS in high resolution reflectron-mode used internal standards to gain high mass accuracy spectra for both $s 4 a$ and $s 4 b$ (Figure 3). After purification, each of the peptides was spotted on a MALDI target containing a mixture of $\alpha$-bag cell peptide (residues 1-9), angiotensin I, acidic peptide, and bovine insulin. The spectra were compared to the monoisotopic mass calculation of the peptides with the predicted PTMs.

The theoretical monoisotopic mass for the s4a peptide ( 30 amino acids) with PTMs of Nterminal pGlu, disulfide bonding between six cysteine residues, O-glycosylation of serine 7 as discussed above, C-terminal amidation, and three hydroxyproline residues is $4080.560 \mathrm{~m} / \mathrm{z}$. The resulting spectra of the s4a fraction yielded a reflectron mass of $4080.471 \mathrm{~m} / \mathrm{z}$ (Figure 3A). This measured value thus differed from the theoretical value by $22 \mathrm{ppm}$.

For the $\mathrm{s} 4 \mathrm{~b}$ peptide (37 amino acids), a theoretical monoisotopic mass was calculated as $4947.088 \mathrm{~m} / \mathrm{z}$, including disulfide bonding between six cysteine residues, pGlu at the Nterminus, O-glycosylation, six hydroxyproline residues, and C-terminal amidation. A highaccuracy measurement of purified $\mathrm{s} 4 \mathrm{~b}$ resulted in an observed mass of $4947.100 \mathrm{~m} / \mathrm{z}$ (Figure 3B), a deviation of $2.4 \mathrm{ppm}$ from the theoretical monoisotopic mass value. These results support the $s 4 \mathrm{a}$ and $\mathrm{s} 4 \mathrm{~b}$ peptide sequences as determined by cDNA and amino acid analyses, including the noted PTMs (without reference to their actual position in the sequence). 


\section{Chemical Treatment to Indicate Glycosylation}

In order to further demonstrate the existence of O-glycosylation, chemical treatment with $\mathrm{NH}_{4} \mathrm{OH}$ was performed on each of the purified peptides. The efficacy of MS to determine removal of O-linked glycosylation from serine and threonine residues in peptides using $\mathrm{NH}_{4} \mathrm{OH}$ has been previously demonstrated (24). The reaction was reported to involve two steps. In the first, the glycan is removed under a $\beta$-elimination reaction, creating a dehydroalanine intermediate. Then $\mathrm{NH}_{3}$ is added across the double-bond of the dehydroalanine via a Michael-type addition. Further, the reaction with $\mathrm{NH}_{4} \mathrm{OH}$ has been shown to leave peptides without glycosylation, as well as C-terminal amides, intact (24). In each experiment, a second peak at $3094 \mathrm{~m} / \mathrm{z}$ and $3961 \mathrm{~m} / \mathrm{z}$ was observed in similar abundance, corresponding to the loss of $\sim 893 \mathrm{Da}$ and demonstrating the presence of the glycan for $\mathrm{s} 4 \mathrm{a}$ and $\mathrm{s} 4 \mathrm{~b}$, respectively.

\section{Peptide Sequence Verification by Mass Spectrometry}

Identification of the peptide sequence for $\mathrm{s} 4 \mathrm{a}$ and $\mathrm{s} 4 \mathrm{~b}$ to this point has included: predicted amino acid sequences from cDNAs, amino acid analysis indicating PTMs, chemical and MS evidence for O-linked $\mathrm{Hex}_{3}$-HexNAc-HexNAc, and accurate mass measurements matching the theoretical peptide masses. Verification of the final amino acid sequences for both peptides was achieved with nanospray ionization (NSI) MS experiments on the reduced and alkylated conotoxins.

Figure 4A illustrates full scan NSI MS peaks from the fully alkylated s4a sample. The abundant peak at $1180.4 \mathrm{~m} / z$ corresponded to the +4 -charged, alkylated s4a peptide with the glycan intact. Peaks observed at 1913.1, 1276.0 and $957.3 \mathrm{~m} / z$ represented the $+2-,+3-$, and +4-charged, MSinduced deglycosylated species of the alkylated peptide, respectively. The reduced and alkylated s4a toxin was subjected to NSI MS ${ }^{2}$ and $\mathrm{MS}^{3}$ experiments that were able to target both the glycosylated and glycan-free peptides.

Fragmentation of the glycan-free molecular ion vastly simplifies sequence interpretation as demonstrated by comparison of Figure 4B with 4C. Figure 4B illustrates a NSI MS ${ }^{2}$ spectrum of the alkylated, glycosylated s4a peptide (+4-charged, $1180.4 \mathrm{~m} / z$ ). Hexose losses were readily observable in the collisionally-induced dissociation (CID) spectra such that few b/y ions could be identified. Figure $4 \mathrm{C}$ details the CID spectrum obtained by isolation and fragmentation of the peak at $1914.3 \mathrm{~m} / z$, corresponding to the alkylated, deglycosylated s4a, $\left(\mathrm{M}_{\mathrm{alk}}+2 \mathrm{H}-\left(\mathrm{Hex}_{3^{-}}\right.\right.$ HexNAc-HexNAc) $)^{2+}$. The assignment of the single, unmodified proline residue at the 6 position was supported by observance of the $b_{6}$ and ion $b_{5}$ ions. The remaining proline residues from the cDNA sequence were hydroxylated as evidenced by the C-terminal fragment loss in each experiment, from $\mathrm{y}_{10}$ to $\mathrm{y}_{9}$, and the combined loss between $\mathrm{y}_{9}$ and $\mathrm{y}_{7}$. A summary of the observed fragments from $\mathrm{MS}^{2}$ experiments and the matching s4a sequence is given in Figure 5A. Furthermore, cleavage of s4a at the N-terminal side of residue 16 with endoprotease Asp$\mathrm{N}$ yields the expected mass fragments by ESI and MALDI MS (data not shown). Collectively, these results strongly support the proposed sequence and PTMs as summarized in Figure 5A.

As with the s4a peptide, the $\mathrm{s} 4 \mathrm{~b}$ conotoxin was reduced and alkylated, purified and subjected to NSI MS and $\mathrm{MS}^{2}$ sequencing experiments. The full-scan MS of the alkylated s4b peptide is depicted in Figure 4D. The two abundant peaks in the spectrum at 1397 and $1118 \mathrm{~m} / \mathrm{z}$ correspond to the +4 - and +5 -charged ions of the fully reduced intact $\mathrm{s} 4 \mathrm{~b}$ peptide, respectively. Deglycosylated peaks, even after optimization, were limited to small signals at $1564 \mathrm{~m} / \mathrm{z}(+3)$, $1174 \mathrm{~m} / z(+4)$ and $940 \mathrm{~m} / z(+5)$. Nevertheless, $\mathrm{MS}^{2}$ spectra were obtained from both glycosylated as well as deglycosylated molecular ions. Figure 4E depicts the $\mathrm{MS}^{2}$ spectrum obtained from the +3 -charged precursor of the alkylated $\mathrm{s} 4 \mathrm{~b}(1397.5 \mathrm{~m} / \mathrm{z})$. As observed with peptide $s 4 a$, the presence of the glycan moiety creates a number of peaks that complicate the spectrum (denoted with double-daggers), which limits the reliable sequence information that 
is obtained. The information yielded by this spectrum was combined with other $\mathrm{MS}^{2}$ spectra: CID of the glycan free species, +4-charged at $1174.2 \mathrm{~m} / \mathrm{z}$ (Figure 4F), and +3-charged at 1564.4 (spectrum not shown). A summary diagram of the fragment identification and the corresponding sequence is given in Figure $5 \mathrm{~B}$. The detection of the $b_{3}, b_{4}$ and $b_{5}$ fragments provide verification of the qKELV N-terminus. The mass difference between the $\mathrm{N}$-terminal $b_{5}$ and $b_{7}$ ions supports the presence of an unmodified proline residue at the sixth position in the sequence. Amino acid analysis of $\mathrm{s} 4 \mathrm{~b}$ confirmed that one proline and six hydroxyproline residues are present. The $\mathrm{N}$-terminal 30 amino acids of $\mathrm{s} 4 \mathrm{a}$ and $\mathrm{s} 4 \mathrm{~b}$ are identical except for the third residue ( $\mathrm{E}$ instead of $\mathrm{S}$ in residue 3 for $\mathrm{s} 4 \mathrm{~b}$ ), which may suggest that glycosylation at the serine 7 position is similar. The prevalence of Ser and Thr residues surrounding the proposed glycosylation site in both toxins provides further support that serine 7 is the site of the modification (25).

\section{Physiological Action of Injected Venom}

Under control conditions, stimulation of the nerve supplying a frog muscle leads to a single AP in motor axons, a single EPP at the neuromuscular junction, and a single AP in the muscle fibers. In our experiments, muscle APs were selectively blocked with the toxin $\mu \mathrm{GIIIA}$, and an EPP resulting from a single nerve shock is illustrated in the upper trace in Figure 6A. In the presence of a 1/1000 dilution of injected venom from C. striatus, a single nerve shock produced an intense burst of EPPs at $\sim 100 \mathrm{~Hz}$ (lower trace in Figure 6A) that could last for more than 6 sec (not illustrated). EPP amplitude and time course were not grossly affected, suggesting that the main action of the toxin is to induce repetitive firing in motor axons or nerve terminals. The concentration threshold for this effect varied between dilutions of $1 / 5,000-1 / 15,000$ of injected venom, depending on the animal. Repetitive EPPs can also occur spontaneously in the presence of injected venom, particularly with higher doses and longer exposure times.

Injected venom had no apparent effect on the frog nerve-muscle preparation in the presence of tetrodotoxin (TTX), a highly selective blocker of $\mathrm{Na}_{\mathrm{v}}$ channels in both nerve and muscle. Although AP-generating mechanisms were thus implicated, the relevant $\mathrm{Na}_{\mathrm{v}}$ channels could be either in the nodes of Ranvier of motor axons or in the nerve terminals themselves. A series of experiments was therefore carried out to identify the anatomical site of toxin action. A segment of nerve, including the cut end, was isolated in its own chamber and separated from the muscle by a Vaseline-gap. When injected venom from $C$. striatus was applied to the compartment containing only the nerve segment, repetitive EPPs were evident, exactly as described above (data not shown). Tests with dye confirmed that there was no leakage between the two chambers. Thus, the active toxins in injected venom appear to have molecular targets localized to nodes of Ranvier, but our experiments cannot rule out the possibility of targets also residing in the non-myelinated nerve terminals on the muscle fibers.

\section{Physiological Effects of s4a- and s4b-Purified Fractions}

Application of a purified fraction of s4a to the frog neuromuscular preparation at concentrations greater than $30 \mathrm{nM}$ was typically sufficient to induce repetitive EPPs evoked by a single motor nerve stimulus (Figure 6B). This effect thus mimics that produced by injected venom, and repetitive firing induced by s4a was also TTX-sensitive. Purified s4b produced qualitatively similar effects (data not shown). Neither s4a nor s $4 b$ had any obvious effect on the frequency of spontaneous transmitter release (detected as miniature EPPs; data not shown), suggesting that these peptides do not directly affect resting calcium levels or membrane potential in nerve terminals.

Voltage-gated Na channels in nodes of Ranvier are candidate targets for s4a and s4b, and we attempted voltage clamp studies to test this idea. Whole-cell patch clamp recordings were made from frog DRG neurons. Injected venom (1:1000 dilution) and purified s4a (concentration 
undetermined, 1:500 dilution) produced a negative shift of 10-15 $\mathrm{mV}$ in the Na conductancevoltage relation. Similar effects were seen with crude venom isolated from the venom duct (1:1,000-2,000 dilutions). Time courses of the Na currents were not obviously affected, except for the apparent shift in voltage-dependence.

\section{DISCUSSION}

Two peptide toxins have been isolated from the injected venom of $C$. striatus and are designated $\mathrm{s} 4 \mathrm{a}$ and $\mathrm{s} 4 \mathrm{~b}$. Each peptide is a major component of the injected venom and is individually capable of producing repetitive firing in frog nerve. This action mimics that of the unfractionated injected venom and probably involves modification of axonal $\mathrm{Na}$ channels. As shown above, the efficacy of the individual peptides, s4a and s4b, stands in contrast to the synergistic effect of two different toxins from $C$. purpurascens, a piscivorous species from the Eastern Pacific (26). This suggests that at least two distinct molecular mechanisms have evolved in the genus Conus for rapid immobilization of fish prey through spastic paralysis: a combination strategy involving both $\mathrm{Na}_{\mathrm{v}}$ - and $\mathrm{K}_{\mathrm{v}}$-channel modifiers, like that seen in $C$. purpurascens, as well as a mechanism requiring only a single peptide as in $C$. striatus.

\section{Structural Characterization of $s 4 a$ and $s 4 b$}

Both $\mathrm{s} 4 \mathrm{a}$ and $\mathrm{s} 4 \mathrm{~b}$ have been characterized by amino acid analysis and MALDI-TOF MS as peptides having 30 and 37 residues and monoisotopic $\mathrm{M}+\mathrm{H}$ of $4080.5 \mathrm{~m} / \mathrm{z}$ and $4947.1 \mathrm{~m} / \mathrm{z}$, respectively. DNA cloning and sequencing from C. striatus venom ducts yielded two likely matches to the peptides observed. With evidence of hydroxyproline residues from amino acid analysis and pGlu and C-terminal amidation from the genetic sequences, the predicted $\mathrm{M}+\mathrm{H}$ of $3188.3 \mathrm{~m} / \mathrm{z}$ for s $4 \mathrm{a}$ and $4054.8 \mathrm{~m} / \mathrm{z}$ for $\mathrm{s} 4 \mathrm{~b}$ could be compared to the measured protonated mass. The monoisotopic mass difference in the theoretical over the observed was $\sim 892.3 \mathrm{Da}$,

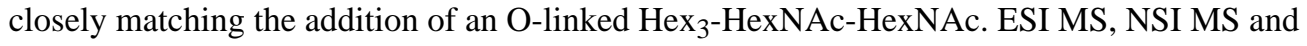
MALDI-TOF MS were used to confirm the presence of Hex and HexNAc moieties, and treatment with $\mathrm{NH}_{4} \mathrm{OH}$ was consistent with an O-glycosylated serine or threonine residue.

We confirm that the sequence for the $b_{5}$ fragment for s4a is qKSLV (where $q$ is pyroGlu) and the singly charged fragment appears at $539 \mathrm{~m} / \mathrm{z}$. This is adjacent to the glycosylated serine portion of the sequence, qKSLV-PS§VIT- (where $\S$ is the $892.8 \mathrm{Da}$ O-linked glycosyl group). The high abundance of the $b_{5}$ ion is likely due to the enhanced cleavage $\mathrm{N}$-terminal to proline residues that has been reported by Wysocki and co-workers $(27,28)$. The observed high intensity $\mathrm{b}_{16}, \mathrm{y}_{14}, \mathrm{y}_{9}$ ions in the MS/MS spectrum of $\mathrm{s} 4 \mathrm{a}$, as well as the $\mathrm{b}_{16}{ }^{+2}, \mathrm{y}_{21}{ }^{+2}$, and $\mathrm{y}_{7}$ ions in the MS/MS spectrum of $\mathrm{s} 4 \mathrm{~b}$, provide additional evidence for favored cleavage Nterminal to proline or hydroxyproline. Furthermore, the presence of the glycosyl group may facilitate the abundant fragmentation of the adjacent $b_{5}$ ion by inhibiting charge transfer along the amide bond, much the same way a basic residue such as R, K, or $\mathrm{H}$ holds a charge and dominates charge-directed fragmentation. As the $b_{5}$ ion is also readily observed in ESI MS and $\mathrm{MS}^{2}$ conditions for the $\mathrm{s} 4 \mathrm{~b}$ peptide ( $\mathrm{qKELV}$ at $581 \mathrm{~m} / \mathrm{z}$ ), an indication is given that Oglycosylation may also be located at the serine position 7 for this peptide. Furthermore, the presence of the $b_{5}$ in both of these peptides illustrates nicely the predicted difference in the $3^{\text {rd }}$ residue in the $\mathrm{N}$-terminal portion of the sequences ( $\mathrm{S}$ for $\mathrm{s} 4 \mathrm{a}$ and $\mathrm{E}$ for $\mathrm{s} 4 \mathrm{~b}$ ).

O-linked glycosylation has been reported previously in Conus toxins $(9,11,29-31)$, but the functional significance of this PTM is not clear. Previous work with glycosylated conotoxins has focused on venoms derived from the venom duct, leaving open the possibility that the Olinked glycan may play some role in secretion within the venom duct but is lost in maturation of the injected toxin. Such a role in secretion remains possible, but loss of the glycan clearly does not occur in the case of $s 4 a$ and $s 4 b$, because the glycosylated state is preserved in the mature toxins injected by the snail during predation. Toxicity of $\kappa A-S I V A(s 4 a)$ isolated from 
the venom duct has been reported to decrease after deglycosylation (11), but such whole-animal experiments can be difficult to interpret, and quantitative physiological measurements have not been described. In another type of Conus toxin, contulakin-G, intracerebral injections of the native $\mathrm{O}$-glycosylated peptide in mice were more effective than with the glycan-free analogue, despite a lower affinity of the glycosylated toxin observed with in vitro binding assays (29). Reasons for this apparent discrepancy are unclear but could be due to the glycosylation modification playing a significant role in the transport of the peptide in vivo. The role of glycosylation and its manipulation in biomolecules affecting folding, structure, stability, uptake and recognition, among other properties, are increasingly being investigated (32).

PTMs of both s4a and s4b have been determined by a combination of amino acid analyses and NSI- MS/MS experiments. The $\mathrm{s} 4 \mathrm{~b}$ toxin was a previously uncharacterized, putative peptide predicted from a cDNA sequence (20). Our work here has confirmed the predicted sequence and further characterized the toxin as

qKELVPS§VITTCCGYDOGTMCOOCRCTNSCOTKOKKO-NH ${ }_{2}$, where q is pGlu, $\S$ is Olinked $\mathrm{Hex}_{3}$-HexNAc-HexNAc, $\mathrm{O}$ is hydroxyproline, and amidation occurs at the C-terminus. Santos et al. (20) correctly predicted the modifications in s4b except that the third residue (Glu) was predicted to be carboxylated. Thus, our results underscore the importance of using MS or other techniques that analyze the venom-isolated toxin, rather than relying on sequence homology to predict mature toxin sequences.

The s $4 \mathrm{~b}$ toxin has a high $\mathrm{N}$-terminal homology to $\mathrm{s} 4 \mathrm{a}$, determined to be qKSLVPS§VITTCCGYDOGTMCOOCRCTNSC-NH ${ }_{2}$, where q is pGlu, $\S$ is O-linked $\mathrm{Hex}_{3}$ HexNAc-HexNAc, O is hydroxyproline, and amidation occurs at the C-terminus. S4a has been reported previously as $\kappa$ A-SIVA (11). Our results for the sequence determination matched the previously reported results, confirming genetic information, amino acid analysis, and MS/MS verification $(11,20,21)$. The combination of the mass spectrometric techniques to perform sequence verification provided information to support the reported toxin sequences and posttranslational modifications.

\section{Mechanism of Action for s4a and s4b Peptides}

Despite the dramatic physiological effects produced by isolated fractions of $\mathrm{s} 4 \mathrm{a}$ and $\mathrm{s} 4 \mathrm{~b}$, and by injected venom, identification of the specific molecular target through physiological experimentation has been surprisingly difficult. Historically, it has been well known that crude duct venom from $C$. striatus is neurotoxic, causing contractions in vertebrate skeletal and cardiac muscle preparations $(33,34)$. Subsequent studies with single myelinated axons (frog) revealed intense repetitive firing produced by crude duct venom, and voltage clamp studies demonstrated that the main effect was a shift in the voltage-dependence of sodium channel activation to more negative voltages (35).

Our preliminary voltage clamp experiments with frog DRG neurons are consistent with this effect. Both s4a and injected venom (as well as crude duct venom) regularly produced a small, negative shift in the voltage-dependence of $\mathrm{Na}_{\mathrm{v}}$ channel activation. Similar experiments were not carried out with s4b due to limited amounts of material. Since both toxins appear to affect $\mathrm{Na}_{\mathrm{V}}$ channels expressed at frog nodes of Ranvier, $\mathrm{Na}_{\mathrm{v}} 1.6$ would be the most likely candidate channel $(36,37)$. We suspect that action of these toxins was partially masked in frog DRG neurons, which express a mixture of $\mathrm{Na}_{\mathrm{v}}$ subtypes (38). Clearly both $\mathrm{s} 4 \mathrm{a}$ and $\mathrm{s} 4 \mathrm{~b}$ toxins merit further testing with heterologously expressed $\mathrm{Na}_{\mathrm{v}} 1.6$ channels as well as other $\mathrm{Na}_{\mathrm{v}}$ subtypes. Additional studies aimed at examination of the mechanisms of action of $\mathrm{s} 4 \mathrm{a}$ and $\mathrm{s} 4 \mathrm{~b}$ on native $\mathrm{Na}_{\mathrm{v}}$ channels will require a more homogenous population of the specific $\mathrm{Na}_{\mathrm{v}}$ isoform targeted by these toxins. 
In conjunction with its initial discovery, the s4a peptide was suggested to block $\mathrm{K}_{\mathrm{V}}$ channels $(6,11)$, but an extremely high concentration of toxin was needed to only partially block K currents through Shaker $\mathrm{K}_{\mathrm{v}} 1$ channels expressed in Xenopus oocytes. We also carried out tests with injected venom and with purified $\mathrm{s} 4 \mathrm{a}$ on $\mathrm{K}_{\mathrm{v}} 1$ channels from several sources expressed in Xenopus oocytes (Drosophila Shaker B $\Delta 6-46$, Xenopus XKv1.1 and XKv1.3, and Lolgio SqKv1.1), but we found no evidence for block of $\mathrm{K}_{\mathrm{v}}$ channels at concentrations well above those that induced repetitive firing in frog nerve (data not shown).

Moreover, as indicated in Figure 6B, the s4a peptide induces repetitive firing in frog nerve in the presence of $12 \mathrm{mM}$ tetraethylammonium, a concentration sufficient to block the three known types of $\mathrm{K}_{\mathrm{v}}$ channels at Xenopus nodes of Ranvier (39). Since TEA itself did not induce repetitive firing (see also (35)), it is clear that block of these $\mathrm{K}_{\mathrm{V}}$ channel subtypes does not mimic the effects of $s 4 a$ or $s 4 b$.

Recently, a peptide of 60 amino acids (conkunitzin-S1) that blocks heterologously expressed Shaker B $\Delta 6-46$ channels has been identified in C. striatus (40), but efficacy of this toxin on native preparations has not been reported, nor is it clear if it is a component of injected venom. Significant differences exist between peptides in the venom duct of $C$. striatus and those injected into prey, and these differences can vary greatly between individual snails (12). This feature makes accounting for the exact mechanism of paralysis of fish prey a challenging problem.

\section{Different Mechanisms of Fish Paralysis in Conus}

Data presented in this paper indicate that $\mathrm{s} 4 \mathrm{a}$ and $\mathrm{s} 4 \mathrm{~b}$, the two predominant peptides typically present in the injected venom of $C$. striatus (14), can individually mimic the spastic paralytic activity seen when this snail injects venom into a living fish. Because $\mathrm{s} 4 \mathrm{a}$ and $\mathrm{s} 4 \mathrm{~b}$ appear to act by augmenting activation of nodal $\mathrm{Na}_{\mathrm{v}}$ channels, injection of these toxins would immediately lead to intense repetitive activity in motor axons, and presumably also in myelinated sensory axons. This aberrant activity would directly invade both the skeletal musculature as well as the spinal cord. This type of single-peptide mechanism of rapid paralysis may be common to all of the members of the molecularly defined clade that includes $C$. striatus because other members have homologous toxins (based on amino acid sequence) that have similar effects (C. consors (9) and C. catus (unpublished)). Abnormal activation of $\mathrm{Na}_{\mathrm{v}}$ channels is a mechanism shared by many scorpion toxins (41).

This mechanism of paralysis would appear to be fundamentally different than that described for $C$. purpurascens, an Eastern Pacific species that also subdues fish with a spastic paralysis. In the latter case, two distinct peptides accomplish this task. One toxin, $\delta$-PVIA, inhibits Nachannel inactivation, whereas the other, $\kappa$-PVIIA, blocks $\mathrm{K}_{\mathrm{V}}$ channels. Both peptides are required to duplicate the paralytic activity seen with whole venom (26). Modification of inactivation of $\mathrm{Na}_{\mathrm{v}}$ channels (41), as well as block of $\mathrm{K}_{\mathrm{V}}$ channels (42), are also mechanisms shared by many scorpion toxins.

Evolution of piscivory probably occurred more than once in Conus. One clade includes $C$. geographus and other snails that paralyze fish in a flaccid state by employing blockers of $\mathrm{Na}_{\mathrm{v}}$ channels (e.g., $\mu$-GIIA). This group shows clear phylogenetic, behavioral, and toxicological differences from the clade containing $C$. striatus and others that produce spastic, rigid paralysis. A distinction between the spastic paralysis employed by C. striatus and C. purpurascens is harder to make on behavioral grounds, but the two molecular mechanisms described above- one peptide versus two as well as the specific mechanisms of action against $\mathrm{Na}_{\mathrm{v}}$ channels - make a stronger case for independent evolution of fish-hunting in these two cases as well. This hypothesis is consistent with the most recent molecular phylogeny which 
places C. purpurascens in a distinct clade with C. ermineus (43), an Atlantic species that also produces a spastic paralysis (10).

\section{Supplementary Material}

Refer to Web version on PubMed Central for supplementary material.

\section{Acknowledgements}

We thank Alex P. Norton for collecting and obtaining venom samples from C. striatus. We also thank Dr. Jon-Paul Bingham and Don Barclay for help with collecting C. striatus, Dr. Gary Strichartz for sharing information on culturing DRG neurons, and Dr. Angie Ribera for providing Xenopus $\mathrm{K}_{\mathrm{V}}$ channel clones. This work was supported by NIH grant NS 31609 (to JVS), Kirschstein NRSA 5F32NS43938 (to JRS), NSF grant IBN 0131788 (to WFG), and a fellowship from the Merck Research Laboratories (to JAJ).

\section{References}

1. Craig AG, Bandyopadhyay P, Olivera BM. Post-translationally modified neuropeptides from Conus venoms. Eur J Biochem 1999;264:271-275. [PubMed: 10491070]

2. Jakubowski JA, Kelley WP, Sweedler JV. Screening for post-translational modifications in conotoxins using liquid chromatography/mass spectrometry: an important component of conotoxin discovery. Toxicon 2006;47:688-99. [PubMed: 16574181]

3. McIntosh JM, Olivera BM, Cruz LJ. Conus peptides as probes for ion channels. Meth Enzymol 1999;294:605-24. [PubMed: 9916250]

4. Duda TF, Kohn AJ, Palumbi SR. Origins of diverse feeding ecologies within Conus, a genus of venomous marine gastropods. Biol J Linn Soc Lond 2001;73:391-409.

5. Jones RM, Bulaj G. Conotoxins - new vistas for peptide therapeutics. Curr Pharm Des 2000;6:1249_ 1285. [PubMed: 10903392]

6. Terlau H, Olivera BM. Conus venoms: a rich source of novel ion channel-targeted peptides. Physiol Rev 2004;84:41-68. [PubMed: 14715910]

7. Layer RT, McIntosh JM. Conotoxins: Therapeutic potential and applications. Marine Drugs 2006;4:119-142.

8. Livett BG, Gayler KR, Khalil Z. Drugs from the sea: conopeptides as potential therapeutics. Curr Med Chem 2004;11:1715-23. [PubMed: 15279578]

9. Le Gall F, Favreau P, Benoit E, Mattei C, Bouet F, Menou JL, Menez A, Letourneux Y, Molgo J. A new conotoxin isolated from Conus consors venom acting selectively on axons and motor nerve terminals through a $\mathrm{Na}^{+}$-dependent mechanism. Eur J Neurosci 1999;11:3134-3142. [PubMed: 10510177]

10. Le Gall F, Favreau P, Richard G, Letourneux Y, Molgo J. The strategy used by some piscivorous cone snails to capture their prey: the effects of their venoms on vertebrates and on isolated neuromuscular preparations. Toxicon 1999;37:985-998. [PubMed: 10484746]

11. Craig AG, Zafaralla G, Cruz LJ, Santos AD, Hillyard DR, Dykert J, Rivier JE, Gray WR, Imperial J, Delacruz RG, Sporning A, Terlau H, West PJ, Yoshikami D, Olivera BM. An O-glycosylated neuroexcitatory Conus peptide. Biochemistry 1998;37:16019-16025. [PubMed: 9819194]

12. Walker CS, Steel D, Jacobsen RB, Lirazan MB, Cruz LJ, Hooper D, Shetty R, DelaCruz RC, Nielsen JS, Zhou LM, Bandyopadhyay P, Craig AG, Olivera BM. The T-superfamily of conotoxins. J Biol Chem 1999;274:30664-30671. [PubMed: 10521453]

13. Hopkins C, Grilley M, Miller C, Shon KJ, Cruz LJ, Gray WR, Dykert J, Rivier J, Yoshikami D, Olivera BM. A new family of Conus peptides targeted to the nicotinic acetylcholine receptor. J Biol Chem 1995;270:22361-22367. [PubMed: 7673220]

14. Jakubowski JA, Kelley WP, Sweedler JV, Gilly WF, Schulz JR. Intraspecific variation of venom injected by fish-hunting Conus snails. J Exp Biol 2005;208:2873-2883. [PubMed: 16043592]

15. Clauser KR, Baker P, Burlingame AL. Role of accurate mass measurement $(+/-10 \mathrm{ppm})$ in protein identification strategies employing MS or MS MS and database searching. Anal Chem 1999;71:2871-2882. [PubMed: 10424174] 
16. Moczydlowski E, Olivera BM, Gray WR, Strichartz GR. Discrimination of muscle and meuronal Namhannel subtypes by binding competition between [3H]saxitoxin and $\mu$-conotoxins. Proc Natl Acad Sci USA 1986;83:5321-5325. [PubMed: 2425365]

17. Gilly WF, Brismar T. Properties of appropriately and inappropriately expressed sodium channels in squid giant axon and its somata. J Neurosci 1989;9:1362-1374. [PubMed: 2539444]

18. Bingham, JP. PhD Thesis. University of Queensland; 1998. Novel toxins from Conus. From taxonomy to toxins.

19. Garden RW, Moroz TP, Gleeson JM, Floyd PD, Li LJ, Rubakhin SS, Sweedler JV. Formation of Npyroglutamyl peptides from N-Glu and N-Gln precursors in Aplysia neurons. J Neurochem 1999;72:676-681. [PubMed: 9930740]

20. Santos AD, McIntosh JM, Hillyard DR, Cruz LJ, Olivera BM. The A-superfamily of conotoxins structural and functional divergence. J Biol Chem 2004;279:17596-17606. [PubMed: 14701840]

21. Wang CZ, Jiang H, Ou ZL, Chen JS, Chi CW. cDNA cloning of two A-superfamily conotoxins from Conus striatus. Toxicon 2003;42:613-9. [PubMed: 14602116]

22. Medzihradszky KF, Gillece-Castro BL, Settineri CA, Townsend RR, Masiarz FR, Burlingame AL. Structure determination of O-linked glycopeptides by tandem mass spectrometry. Biomed Environ Mass Spectrom 1990;19:777-781. [PubMed: 1708302]

23. Medzihradszky KF, Gillececastro BL, Townsend RR, Burlingame AL, Hardy MR. Structural elucidation of O-linked glycopeptides by high energy collision-induced dissociation. J Am Soc Mass Spectrom 1996;7:319-328.

24. Rademaker GJ, Pergantis SA, Blok-Tip L, Langridge JI, Kleen A, Thomas-Oates JE. Mass spectrometric determination of the sites of O-glycan attachment with low picomolar sensitivity. Anal Biochem 1998;257:149-160. [PubMed: 9514784]

25. Mirgorodskaya E, Hassan H, Wandall HH, Clausen H, Roepstorff P. Partial vapor-phase hydrolysis of peptide bonds: a method for mass spectrometric determination of O-glycosylated sites in glycopeptides. Anal Biochem 1999;269:54-65. [PubMed: 10094775]

26. Terlau H, Shon KJ, Grilley M, Stocker M, Stuhmer W, Olivera BM. Strategy for rapid immobilization of prey by a fish-hunting marine snail. Nature 1996;381:148-151. [PubMed: 12074021]

27. Breci LA, Tabb DL, Yates JR, Wysocki VH. Cleavage N-terminal to proline: analysis of a database of peptide tandem mass spectra. Anal Chem 2003;75:1963-1971. [PubMed: 12720328]

28. Tabb DL, Smith LL, Breci LA, Wysocki VH, Lin D, Yates JR. Statistical characterization of ion trap tandem mass spectra from doubly charged tryptic peptides. Anal Chem 2003;75:1155-1163. [PubMed: 12641236]

29. Craig AG, Norberg T, Griffin D, Hoeger C, Akhtar M, Schmidt K, Low W, Dykert J, Richelson E, Navarro V, Mazella J, Watkins M, Hillyard D, Imperial J, Cruz LJ, Olivera BM. Contulakin-G, an O-glycosylated invertebrate neurotensin. J Biol Chem 1999;274:13752-13759. [PubMed: 10318778]

30. Kalume DE, Stenflo J, Czerwiec E, Hambe B, Furie BC, Furie B, Roepstorff P. Structure determination of two conotoxins from Conus textile by a combination of matrix-assisted laser desorption/ionization time-of-flight and electrospray ionization mass spectrometry and biochemical methods. J Mass Spectrom 2000;35:145-156. [PubMed: 10679974]

31. Rigby AC, Lucas-Meunier E, Kalume DE, Czerwiec E, Hambe B, Dahlqvist I, Fossier P, Baux G, Roepstorff P, Baleja JD, Furie BC, Furie B, Stenflo J. A conotoxin from Conus textile with unusual post-translational modifications reduces presynaptic $\mathrm{Ca}^{2+}$ influx. Proc Natl Acad Sci USA 1999;96:5758-5763. [PubMed: 10318957]

32. Borman S. Glycosylation engingeering: Controlling personalities tame wild sugars on proteins and natural products. 2006;84

33. Endean R, Gyr P, Surridge J. The pharmacological actions on guinea-pig ileum of crude venoms from the marine gastropods Conus striatus and Conus magus. Toxicon 1977;15:327-337. [PubMed: 882996]

34. Endean R, Surridge J, Gyr P. Some effects of crude venom from the cones Conus striatus and Conus magus on isolated guinea-pig atria. Toxicon 1977;15:369-374. [PubMed: 20679]

35. Hahin R, Wang GK, Shapiro BI, Strichartz G. Alterations in sodium channel gating produced by the venom of the marine mollusc Conus striatus. Toxicon 1991;29:245-259. [PubMed: 1646501] 
36. Caldwell JH, Shaller KL, Lasher RS, Peles E, Levinson SR. Sodium channel Nav1.6 is localized at nodes of Ranvier, dendrites and synapses. Proc Natl Acad Sci USA 2000;97:5616-5620. [PubMed: 10779552]

37. Krzemien DM, Schaller KL, Levinson SR, Caldwell JH. Immunolocalization of sodium channel isoform NaCh6 in the nervous system. J Comp Neurol 2000;420:70-83. [PubMed: 10745220]

38. Campbell DT. Large and small vertebrate sensory neurons express different $\mathrm{Na}$ and $\mathrm{K}$ channel subtypes. Proc Natl Acad Sci USA 1992;89:9569-9573. [PubMed: 1329102]

39. Jonas P, Brau ME, Hermsteiner M, Vogel W. Single-channel recording in myelinated nerve fibers reveals one type of Na channel but different K channels. Proc Natl Acad Sci USA 1989;86:72387242. [PubMed: 2550937]

40. Bayrhuber M, Vijayan V, Ferber M, Graf R, Korukottu J, Imperial J, Garrett JE, Olivera BM, Terlau $\mathrm{H}$, Zweckstetter M, Becker S. Conkunitzin-S1 is the first member of a new Kunitz-type neurotoxin family. Structural and functional characterization. J Biol Chem 2005;280:23766-70. [PubMed: 15833744]

41. Rodriguez de la Vega RC, Possani LD. Overview of scorpion toxins specific for Na+ channels and related peptides: biodiversity, structure-function relationships and evolution. Toxicon 2005;46:83144. [PubMed: 16274721]

42. Tenenholz TC, Klenk KC, Matteson DR, Blaustein MP, Weber DJ. Structural determinants of scorpion toxin affinity: the charybdotoxin (alpha-KTX) family of $\mathrm{K}(+)$-channel blocking peptides. Rev Physiol Biochem Pharmacol 2000;140:135-85. [PubMed: 10857399]

43. Duda TF, Kohn AJ. Species-level phylogeography and evolutionary history of the hyperdiverse marine gastropod genus Conus. Mol Phylogenet Evol 2005;34:257-272. [PubMed: 15619440] 


\section{s4a MGMRMMFTVFLLVVLATNVVSTPSDRASDGRNAAVHER [QKSLVPSVITTCCGYDPGTMCPPCRCTNSC]G s4h MGMRMMFTVFLSVVLATTVVSTPSDRASDGRNAAVHER [QKELVPSVITTCCGYDPGTMCPPCRCTNSCPTKPKKP]GRRND}

FIGURE 1.

cDNA Predicted Sequences. Venom duct mRNA was isolated from individual snails, converted to double-stranded complementary DNA (cDNA), and cloned to create a cDNA library. Random clones were sequenced and peptide toxin coding clones were selected, yielding putative amino acid sequences for $\mathrm{s} 4 \mathrm{a}$ and $\mathrm{s} 4 \mathrm{~b}$. The precursor sequences are shown with the mature conopeptide sequences in brackets. 

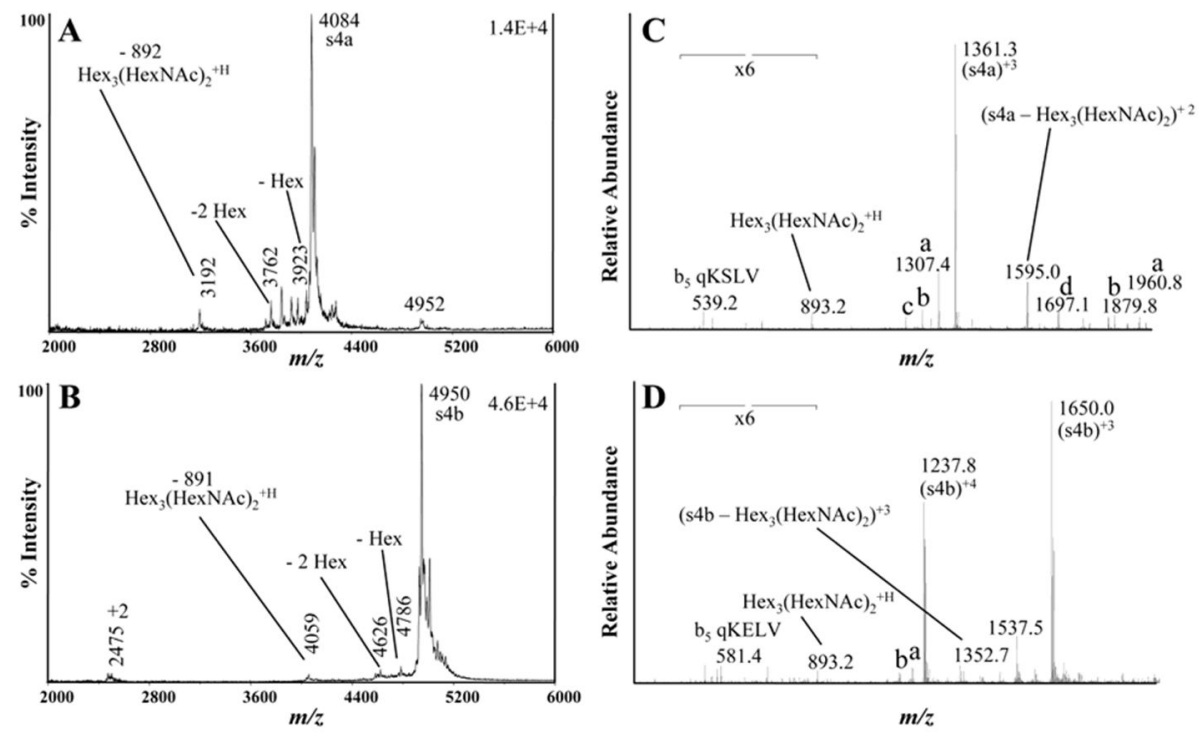

FIGURE 2.

MALDI MS and HPLC-ESI MS of $\mathrm{s} 4 \mathrm{a}$ and $\mathrm{s} 4 \mathrm{~b}$ milked venom fractions. MALDI-TOF MS in linear mode of (A) s4a, and (B) s4b. The glycosylation for s4a and s4b is observed. Full LCESI-ion trap MS data for (C) s4a, and (D) $s 4 b$ is shown. Approximate retention times for $s 4 a$ and s4b were 13.7 and $15.2 \mathrm{~min}$, respectively. a,b,c,d = Peaks corresponding to glycosyl losses; toxin $-\mathrm{Hex}$, toxin $-2 \mathrm{Hex}$, toxin $-3 \mathrm{Hex}$, and toxin $-\mathrm{Hex}_{3} \mathrm{NAc}$, respectively. 


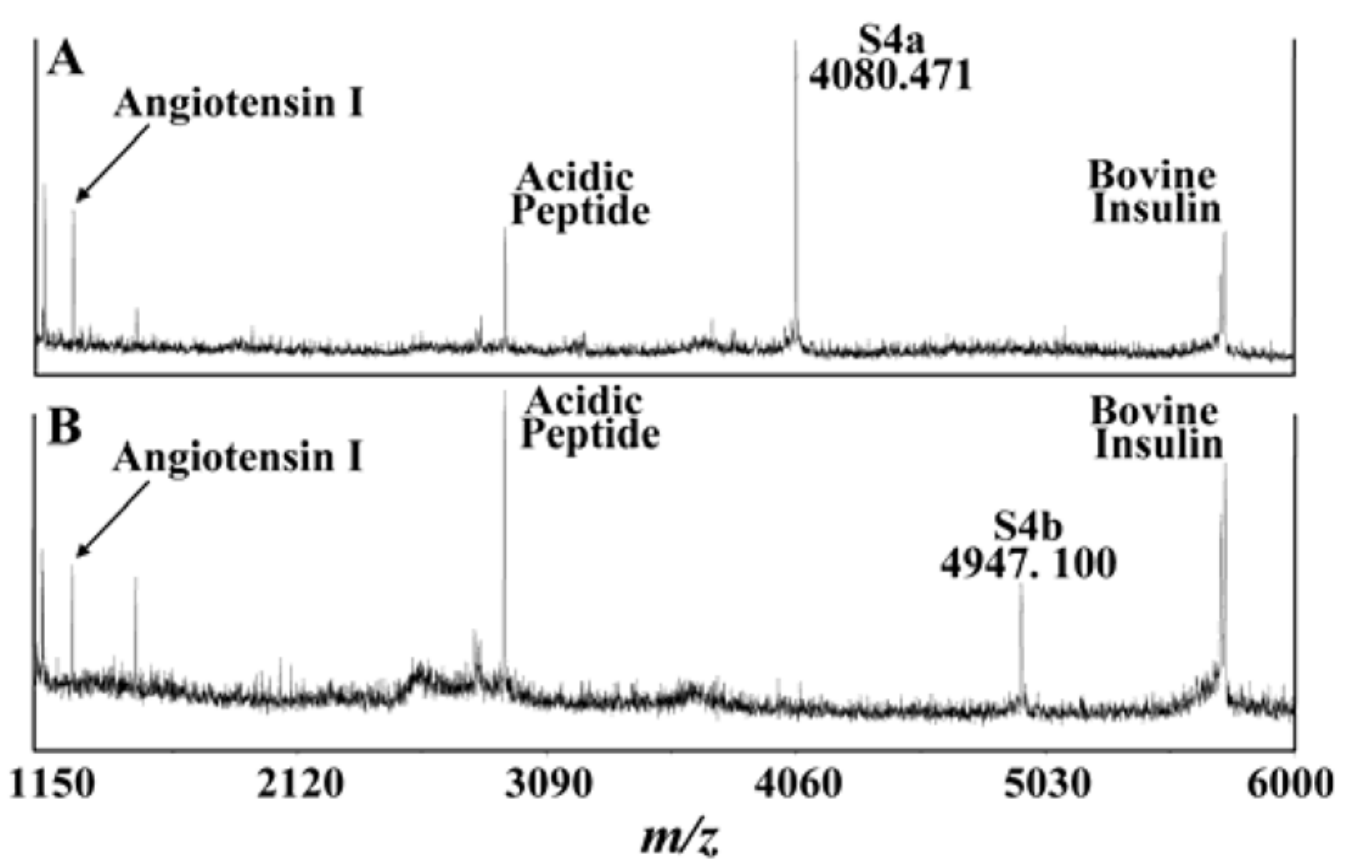

FIGURE 3.

Accurate mass MALDI MS in reflectron mode of (A) s4a, and (B) s4b, using internal standards as described in the experimental section. Based on PTMs determined by amino acid analysis and MS (data shown later), the theoretical mass of s4a is $4080.560 \mathrm{Da}$ while the theoretical mass of s $4 b$ is $4947.088 \mathrm{Da}$. Mass differences of the observed s4a and s4b from the theoretical masses are $22 \mathrm{ppm}$ and $2.4 \mathrm{ppm}$, respectively. 

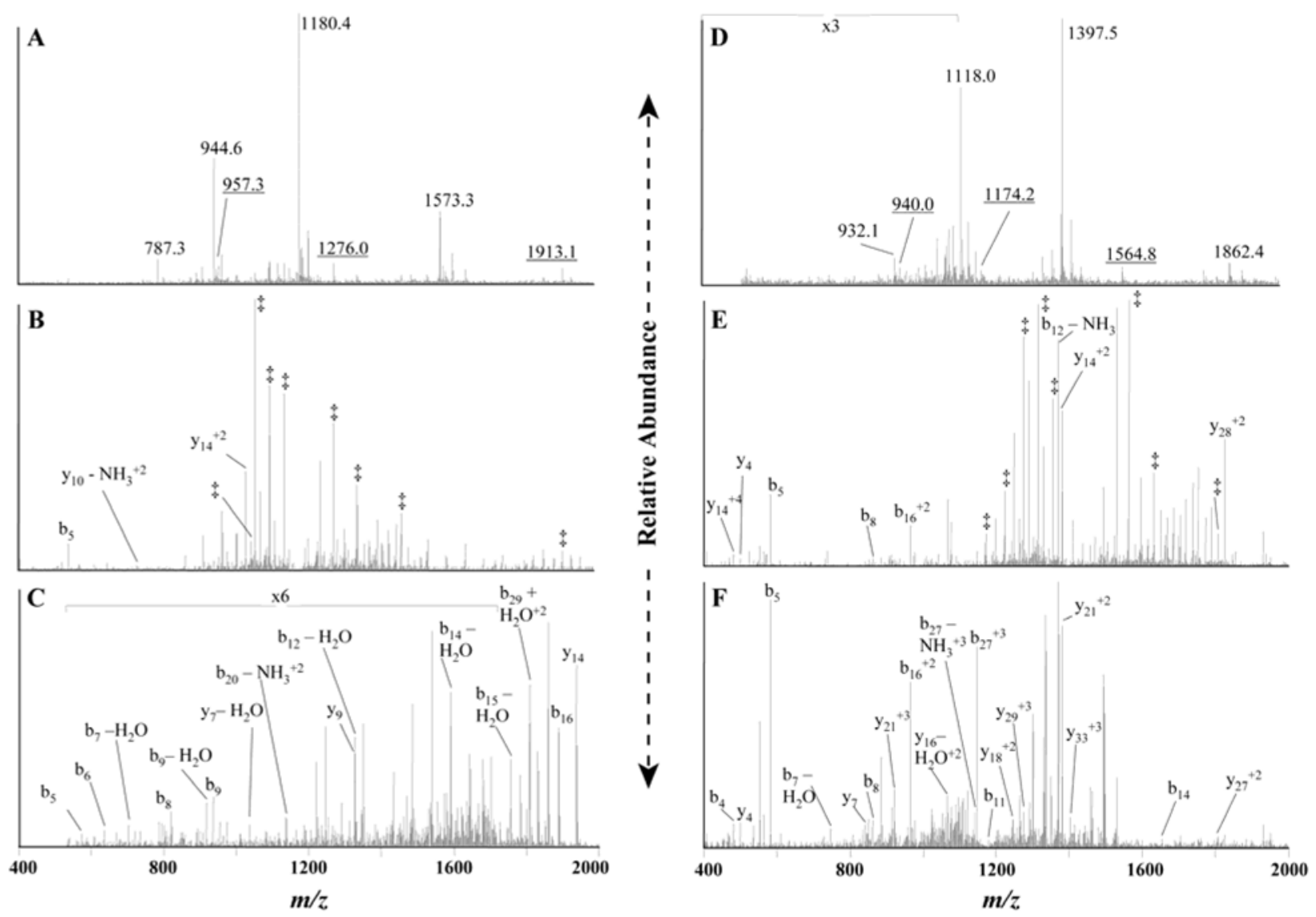

FIGURE 4.

NSI MS CID spectra for s4a and s4b purified venom fractions. (A) Full MS of purified fraction of fully reduced and alkylated s4a. Underlined masses represent deglycosylated peaks. Unlabeled peaks correspond to other minor alkylation products. (B) CID spectrum of $\mathrm{m} / \mathrm{z}$ 1180.4 (fully reduced and alkylated s4a with glycosyl, +4). (C) CID spectrum of $\mathrm{m} / \mathrm{z} 1914.3$ (fully reduced and alkylated s4a without glycosylation, +2). (D) Full MS of purified fraction of fully reduced and alkylated s4b. (E) CID spectrum of $m / z 1397.5$ (fully reduced and alkylated s4b with glycosyl, +4). (F) CID spectrum of $m / z 1174.2$ (fully reduced and alkylated s4b without glycosylation, +4$)$. $\neq=$ peaks related to hexose losses. 


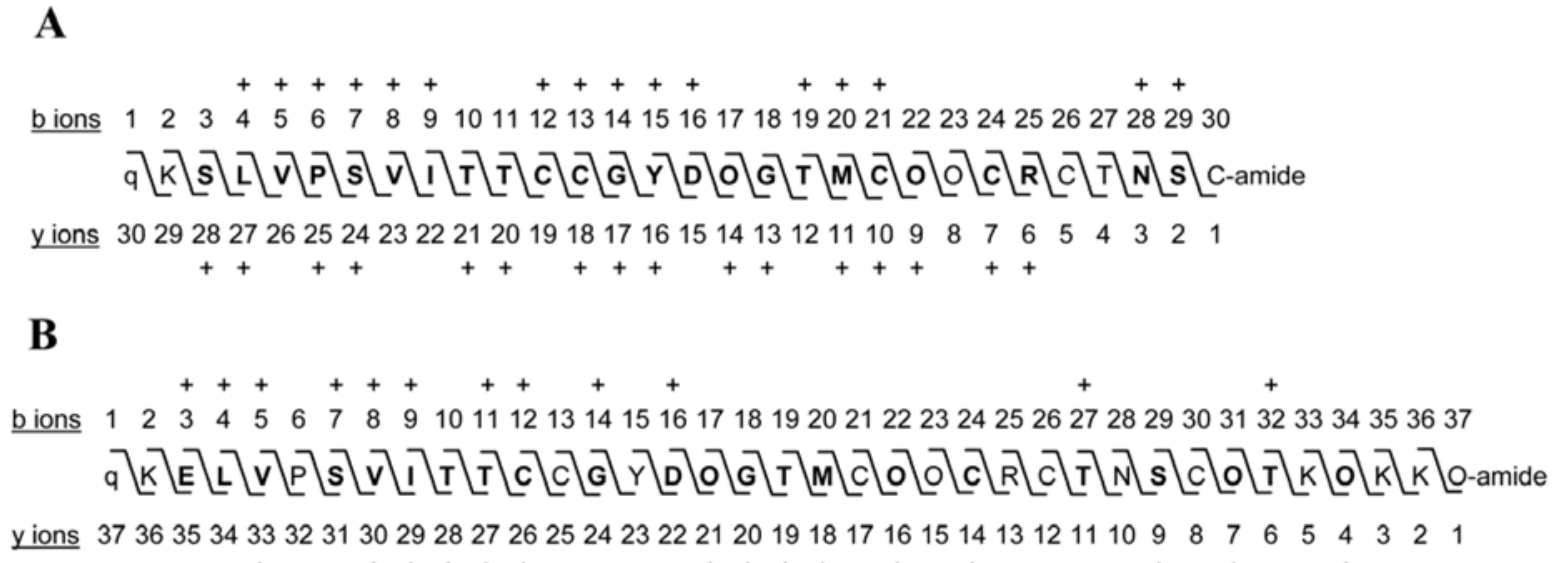

B

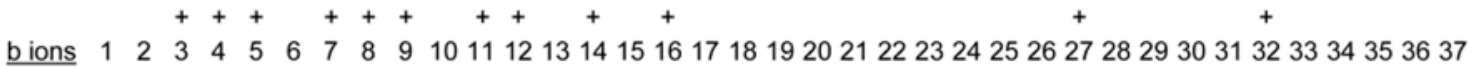

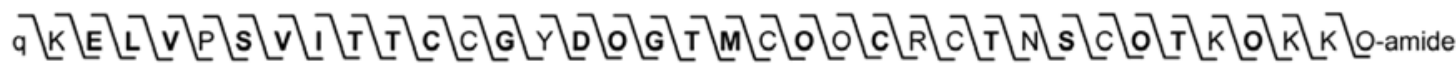

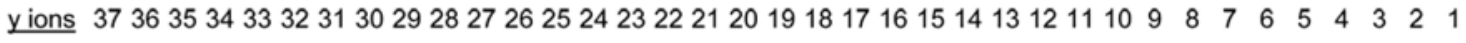

FIGURE 5.

CID sequence verification summary diagram. Sequence verification for (A) s4a, and (B) s4b, showing a modified ladder diagram of detected b/y ions. CID was performed on a number of charge states of the fully reduced and alkylated peptides that led to additional b/y ion assignments other than shown in Figure 4. $+=$ b/y ion was detected. Bolded amino acid designations represent masses directly confirmed by MS. Other amino acid assignments are supported by mass differences. $\mathrm{O}=$ hydroxyproline; $\mathrm{q}=$ pyroglutamic acid. 


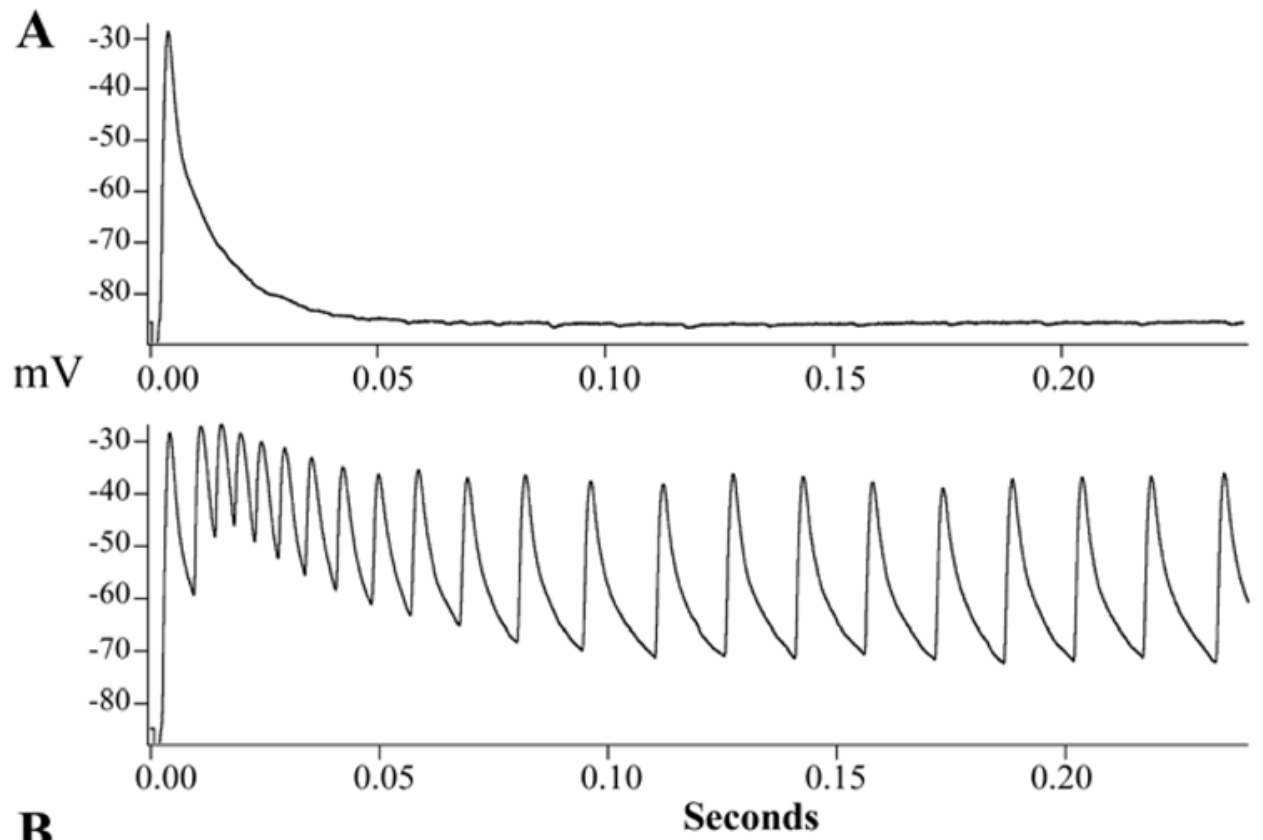

B

Control trace

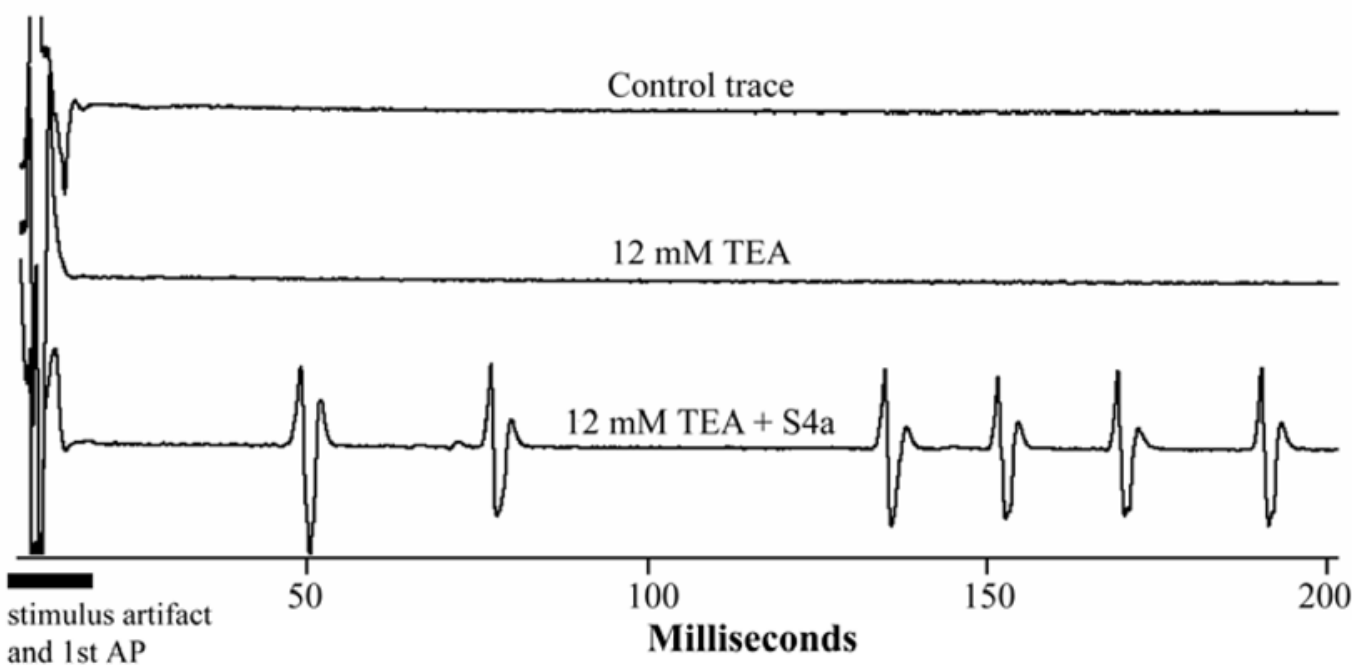

FIGURE 6.

Effects of injected venom from $C$. striatus and s4a peptide. (A) EPPs recorded from cutaneous pectoris muscle fibers following nerve stimulation. Muscle APs were blocked with $\mu$ GIIIA toxin. Upper trace shows the normal response to a single nerve shock. Lower trace shows the repetitive discharge after addition of injected venom to the saline (1:1,000 dilution). Neither the time course nor amplitude of the EPP is noticeably altered by the toxin. (B) Muscle APs recorded with a focal extracellular electrode in response to a single nerve shock in standard saline (upper trace), following the addition of $12 \mathrm{mM}$ tetraethylammonium (TEA, middle trace), and after addition of purified s4a (lower trace). The first AP near time zero is obscured by the stimulus artifact. TEA does not induce repetitive firing on its own, but s4a application (in the presence of TEA in this experiment) mimics the action of injected venom. Application of s4a peptide in the absence of TEA also induces repetitive firing (not shown). Similar results were obtained with purified $s 4 b$ (not shown). 